\title{
Tema Berwawasan Lingkungan Pada Konsep Desain Pengembangan Tempat Pelelangan Ikan dan Wisata Kuliner di Tambak Cemandi, Sidoarjo
}

\author{
Ainur Rizka Maulidiana ${ }^{1}$, Siti Azizah ${ }^{2}$, Ika Ratniarsih ${ }^{3}$ \\ 1,2,3Jurusan Arsitektur, Fakultas Teknik Sipil dan Perencanaan, Institut Teknologi Adhi Tama Surabaya \\ Email: ${ }^{1}$ maulidiana83@gmail.com
}

\begin{abstract}
Sidoarjo has great potential in the development of the fisheries sector, on of them is located in Tambak Cemandi, Sidoarjo Regency, East Java. Tambak Cemandi, has a local scale fish auction. Because this fish auction is close to the sea and the place is not suitable for use, so it is very potential to be developed as a tourist destination and is very attractive as a culinary tourism spot with a special menu of sea fish. The application of the design for the development of fish auction places and culinary tours is with the theme of Architectural Insightful. Architecture with its own environmental insight as a response to the local climate and to reduce the smell of activities carried out in the fish processing area. The methods used in designing this project are observation, interview, data analysis, and documentation. The development that will be carried out in this project is to improve the fish auction area and add facilities to facilities that do not yet exist. The theme raised is environmentally sound architecture with macro natural architectural concepts. To support the macro concept raised, there is a micro concept of attractive forms that are applied to the game and the colors that stand out to show the attractive form concept. Micro has a functional space concept which aims to create a functional space design effectively by optimizing the lighting system in the room, the room in the fish auction is open in design so that air circulation can go in and out freely. For micro, the concept of land layout uses a directed concept where visitors and employees are distinguished from the parking area to the entrance to the land, when visitors enter the dropping area, visitors will be directed to the dropping area and then enter the area with a recreational land layout design where the design makes visitors directed. the way when on the site. Keywords: Fish Auction, Culinary Tourism, Architectural Insightful, Attractive, Functional, Recreational
\end{abstract}

Abstrak. Sidoarjo memiliki potensi besar dalam pengembangan sektor perikanan, salah satunya di Tambak Cemandi, Kabupaten Sidoarjo, Jawa Timur. Tambak Cemandi, memiliki tempat pelelangan ikan skala lokal. Karena tempat pelelangan ikan ini berdekatan dengan laut dan tempatnya kurang layak untuk digunakan sehingga sangat potensial untuk dikembangkan sebagai destinasi wisata dan sangat menarik juga digunakan sebagai tempat wisata kuliner dengan menu khusus ikan laut. Penerapan desain pengembangan tempat pelelangan ikan dan wisata kuliner ini yaitu dengan tema arsitektur berwawasan lingkungan. Arsitektur berwawasan lingkungan tersendiri sebagai respon terhadap iklim daerah setempat serta untuk mengurangi bau dari aktifitas yang dilakukan di area pengolahan ikan tersebut. Metode yang digunakan dalam perancangan proyek ini yaitu observasi, interview, Analisa data, dan dokumentasi. Pengembangan yang akan dilakukan pada proyek ini yaitu memperbaiki area tempat pelelangan ikan dan menambah fasilitas dari fasilitas yang belum ada. Tema yang diangkat yaitu arsitektur berwawasan lingkungan dengan makro konsep arsitektur alami. Untuk mendukung makro konsep yang diangkat maka ada mikro konsep bentuk atraktif yang di terapkan pada permainan dan pewarnaan yang menonjol untuk menunjukan konsep bentuk atraktif tersebut. Mikro konsep ruangnya fungsional yang bertujuan untuk mencipatakan desain ruang fungsional secara efektif dengan mengoptimalkan sistem pencahayaan pada ruangan tersebut, ruangan pada tempat pelelangan ikan di desain terbuka agar sirkulasi udara dapat keluar masuk secara bebas. Untuk mikro konsep tatanan lahan menggunakan konsep terarah yang dimana pengunjung dan karyawan dibedakan untuk area parkir hingga pintu masuk ke lahan tersebut, pengunjung ketika masuk akan diarahkan ke dropping area lalu masuk ke area tersebut dengan desain tatanan lahan rekretaif yang dimana desain tersebut manjadikan pengunjung akan terarah jalannya ketika berada di dalam site tersebut.

Kata Kunci: Tempat Pelelangan Ikan, Wisata Kuliner, Arsitektur Berwawasan Lingkungan, Atraktif, Fungsional, Rekreatif 


\section{Pendahuluan}

TPI Tambak Cemandi yang berada di Kabupaten Sidoarjo ini merupakan pusat penjualan ikan yang cukup besar, cukup lengkap dan terdapat berbagai macam jenis ikan yang diinginkan. Ikan yang dijual juga tidak hanya dari pertambakan sekitar daerah Kabupaten Sidoarjo saja, melainkan dari beberapa daerah.

TPI Tambak Cemandi tersebut kondisinya memang seperti sudah tidak layak untuk ditempati, maka dari itu sangat potensial untuk dikembangkan dan sangat menarik juga digunakan sebagai tempat wisata kuliner. Tema Berwawasan Lingkungan Pada Pengembangan Tempat Pelelangan Ikan dan Wisata Kuliner di Tambak Cemandi, Sidoarjo diangkat karena bangunan yang akan dirancang merupakan bangunan yang membutuhkan banyak sirkulasi udara agar area tersebut tidak bau. Penerapan arsitektur berwawasan lingkungan pada rancangan desain tersebut dengan cara terdapat banyak vegetasi yang berada di area site guna untuk mengurangi suhu yang panas pada area tropis tersebut. Bangunan banyak yang di desain terbuka karena kondisi angin di daerah tersebut cukup kencang jadi sirkulasi udara dapat bebas keluar masuk ke dalam bangunan.

\section{Tinjauan Pustaka}

Heinz Frick (2006) mengatakan bahwa pendekatan arsitektur berwawasan lingkungan yaitu dengan cara menyesuaikan lingkungan alam setempat, penghematan sumber energi alam yang tidak dapat diperbarui, memelihara dengan baik sumber lingkungan alami yaitu (udara, tanah, air), mengurangi ketergantungan pada sistem energi listrik, air dan limbah (limbah air maupun limbah sampah), serta merawat dengan baik gerakan alam untuk mendekati sebuah desain rancangan yang akan diterapkan pada tema tersebut. (Frick \& Suskiyatno, 2007).

Wiyono Wibosono (2005) mengartikan Tempat Pelelangan Ikan (TPI) merupakan tempat yang memiliki fungsi utama dalam kegiatan perikanan serta salah satu pergerakan untuk mengembangkan sebuah usaha seorang penjual ikan segar dan mensejahterakan hidup seorang nelayan. Pelelangan Ikan tersebut sudah berdiri dan diselenggarakan sejak tahun 1922 oleh Koperasi Perikanan di Pulau Jawa dengan tujuan membantu para nelayan untuk mendapatkan harga yang layak. (Wibisono, 2005)

Echols dan Shadily (2007) berkata bahwa wisata kuliner merupakan perjalanan para wisatawan dapat menikmati makanan/masakan dengan ciri khas pada daerah atau negara yang dikunjunginya. Agar dapat menarik kedatangan para wisatawan, wisata kuliner tersendiri harus menciptakan makanan dan minuman dengan sesuatu hal yang berbeda dan menarik untuk dikunjungi. (Putri et al., 2013)

Dalam penelitian Siti Azizah (2007) untuk menciptakan sebuah estetika pada lingkungan yang terkait dengan pedagang kaki lima/tempat wisata kuliner di pusat kota dengan mengupayakan model penataan fisik berupa penzoningan tempat wisata kuliner tersebut sesuai dengan jenis model dagangannya, mengatur penempatannya, mengatur ukuran, bentuk alat jual, dan ruang gerak yang bebas yang cukup leluasa bagi pejalan kaki. (Azizah, n.d. 2007)

\section{Metode Penelitian}

Jenis metode yang digunakan dalam menyusun Konsep Desain TPI (Tempat Pelelangan Ikan) dan Wisata Kuliner di Tambak, Cemandi, Sidoarjo ini menggunakan jenis penelitian deskriptif kualitatif (observasi, interview, analisa data dan dokumentasi). Menurut Moleong (2001) penelitian kualitatif yaitu suatu prosedur yang menghasilkan sebuah data deskriptif yang tertulis, lisan dari seseorang, atau perilaku yang dapat diamati. Hal ini, data yang diperoleh dengan menggunakan pengamatan secara langsung dengan objek studi yang berhubungan dengan judul yaitu tempat pelelangan ikan dan wisata kuliner serta arsitektur berwawasan lingkungan, gunu untuk mengetahui program ruang, sifat dan karakteristiknya, kondisi tapak, serta mengetahui kondisi lingkungan yang ada disekitar. (Moleong. 2000) 


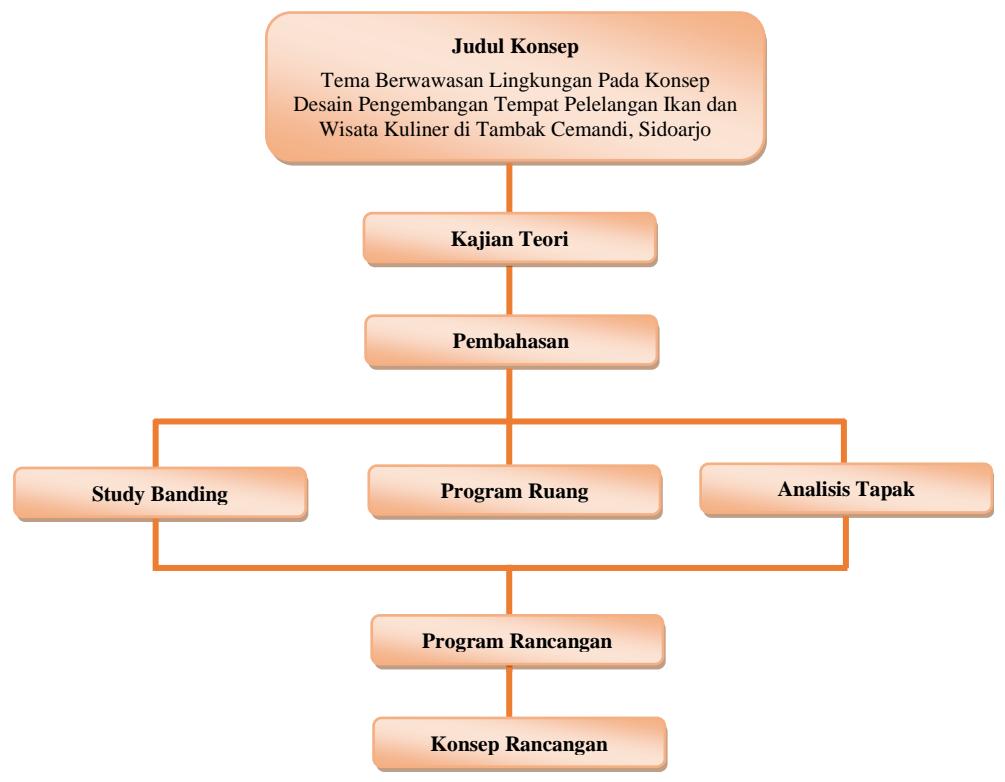

Gambar 1. Diagram Metodologi

Sumber: dokumentasi pribadi

\section{Hasil dan Pembahasan}

\subsection{Studi Banding}

a. Pelabuhan Perikanan di Paiton, Kabupaten Probolinggo
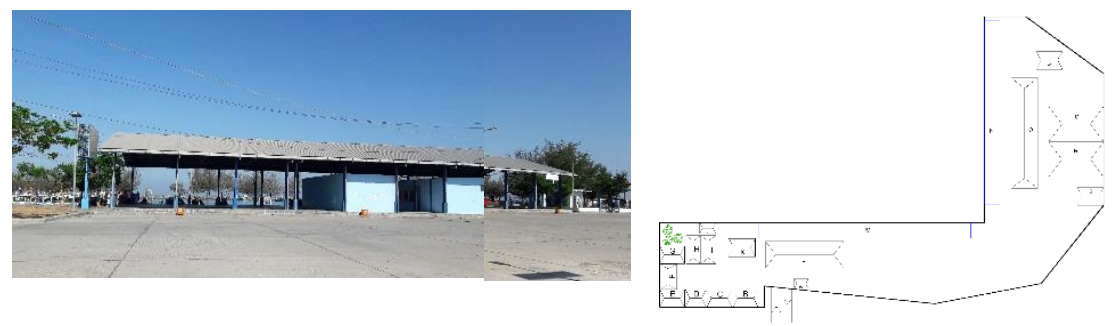

Gambar 2. Pelabuhan Perikanan di Paiton, Probolinggo

Sumber: dokumentasi pribadi

Tempat pelelangan ikan Pelabuhan Perikanan di Paiton, Kabupaten Probolinggo memiliki :

- Bentuk : Dalam mendesain bentuk bangunannya menggunakan desain arsitektur tropis, geometri bangunannya berbentuk persegi panjang, penggunaan atap dari seng/asbes mengakibatkan bangunan semakin terasa panas, bangunan TPI ini memang memiliki sifat bangunan terbuka yang sehingga semua aktifitas dapat terlihat oleh siapapun, bangunannya juga banyak yang tidak memiliki dinding massif.

- Ruang : Kondisi didalam ruangan pada TPI ini tidak begitu lembab, pencahayaan alami pada TPI ini sangat optimal, stand penjualannya masih belum tertata. Jadi, penjual masih belum mendapatkan tempat yang permanen, balai pelelangan dengan pasar menyatu, ruangannya tidak becek, ruangan pada TPI Paiton ini tidak ada dinding penyekat.

- Tata lahan : Menggunakan sistem one gate untuk pengunjung, jalur sirkulasi didalam area lahan juga dapat dicapai dari pemukiman para nelayan sekitar, memiliki area parkir yang cukup luas untuk pengunjung, pengolahan sampah yang cukup baik dengan di sediakannya beberapa tempat sampah di area TPI tersebut. 
b. TPI Ujung Merah di Mangunharjo, Mayangan, Kota Probolinggo
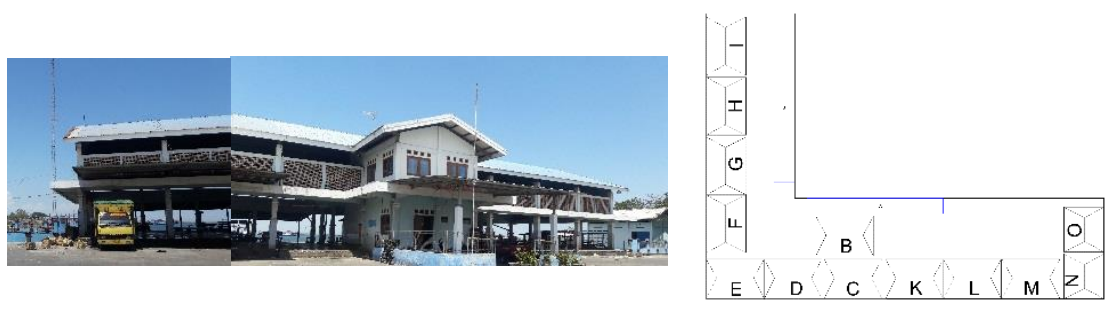

Gambar 3. TPI Ujung Merah di Mangunharjo, Mayangan, Probolinggo Sumber: dokumentasi pribadi

Tempat pelelangan ikan Ujung Merah di Mangunharjo, Mayangan, Probolinggo memiliki konsep:

- Bentuk: Dalam mendesain bentuk bangunannya menggunakan desain arsitektur tropis, penggunaan atap dari asbes mengakibatkan bangunan semakin terasa panas, bangunan TPI ini memang memiliki sifat bangunan terbuka yang sehingga semua aktifitas dapat terliat oleh siapapun.

- Ruang: Kondisi didalam ruangan pada TPI ini sangat lembab, pencahayaan alami pada TPI ini kurang optimal meskipun banyak menggunakan pencahayaan alami dan memiliki banyak bukaan.

- Tata lahan: Menggunakan sistem one gate untuk pengunjung dimana pengunjung dan pengelola melalui jalur sirkulasi yang sama, memiliki area parkir yang khusus dan cukup luas untuk pengunjung, Pengolahan sampah yang kurang baik dengan kurang disediakan tempat sampah pada area TPI Ujung Merah tersebut.

c. Wisata Kuliner Seafood di Jl. Sukolilo 7 No.24, Kedung Cowek, Kec. Bulak, Kota SBY, Jawa Timur
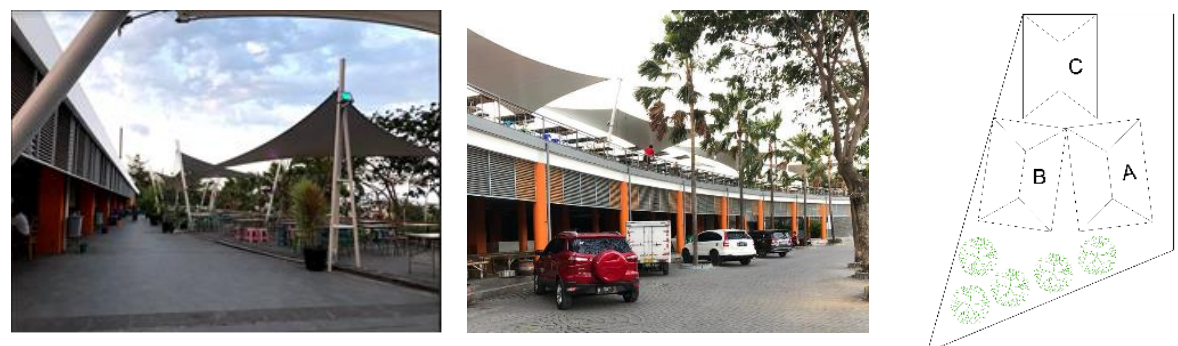

Gambar 4. Wisata Kuliner Seafood Kedung Cowek, Surabaya Sumber: dokumentasi pribadi

Tempat wisata kuliner seafood di Jl. Sukililo 7 No. 24, Kedung Cowek, Kec. Bulak, Kota Surabaya memiliki konsep:

- Bentuk: Dalam mendesain bentuk bangunannya menggunakan desain arsitektur tropis, bangunannya bersifat terbuka.

- Ruang: Kondisi didalam ruangannya cukup baik dan teratur, Pencahayaan alami pada tempat ini kurang optimal meskipun banyak menggunakan pencahayaan alami dan memiliki banyak bukaan.

- Tata lahan: Menggunakan sistem one gate untuk pengunjung dimana pengunjung dan pengelola melalui jalur sirkulasi yang sama, Memiliki area parkir yang kurang luas, pengolahan sampah yang baik jadi tempat tersebut telihat bersih dan nyaman. Serta adanya banyak vegetasi di area tersebut.

\subsection{Program Ruang}

Hal yang dilakukan pada program ruang yaitu melakukan proses identifikasi dan mendefinisikan kebutuhan-kebutuhan perancangan tersebut, serta untuk kebutuhan pengguna. Pada aspek-aspek yang sudah 
dijelaskan yaitu berdasarkan: kebutuhan ruang, besaran ruang, organisasi ruang, diagram ruang, dan persyaratan ruang. Berikut merupakan program ruang pada Tempat Pelelangan Ikan di Tambak Cemandi, Sidoarjo.

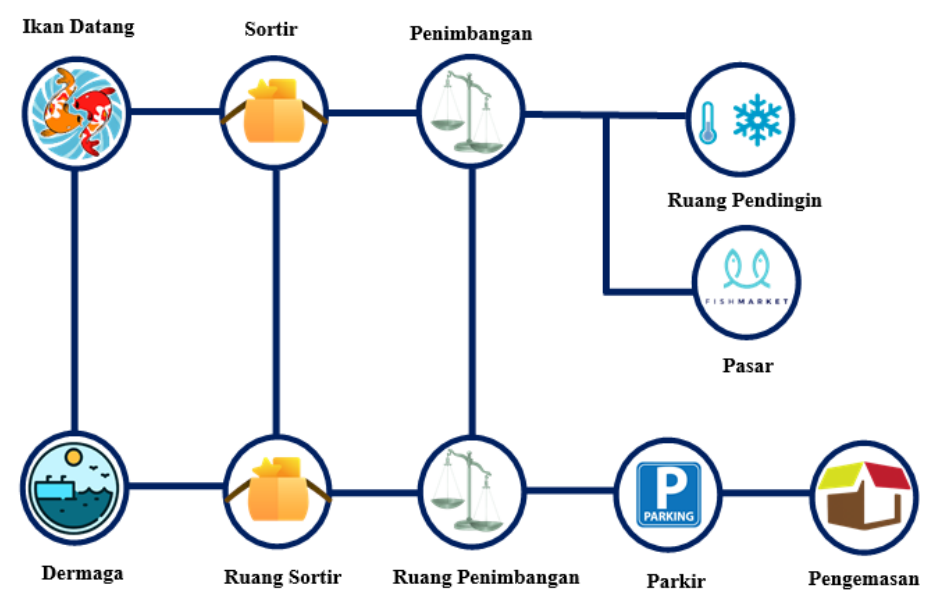

Gambar 5. Aktifitas yang dilakukan

Sumber: dokumentasi pribadi

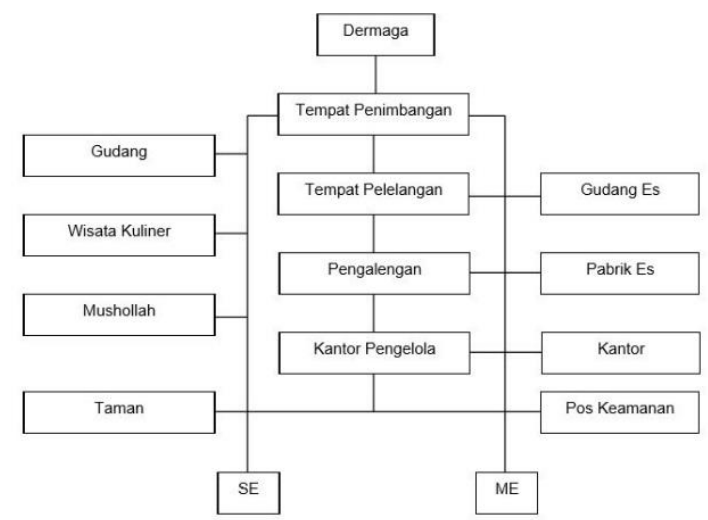

Gambar 6. Organisasi ruang

Sumber: dokumentasi pribadi

Tabel 1. Jenis dan Besaran Ruang

\begin{tabular}{|l|r|}
\hline \multicolumn{1}{|c|}{ Jenis Ruang } & \multicolumn{1}{|c|}{ Besaran Ruang } \\
\hline Fasilitas Utama & $208.00 \mathrm{~m}^{2}$ \\
1. Kantor & $511.00 \mathrm{~m}^{2}$ \\
2. Balai Pelelangan Ikan & $328.00 \mathrm{~m}^{2}$ \\
3. Cold Storage & $706.00 \mathrm{~m}^{2}$ \\
4. Wisata Kuliner & $86.00 \mathrm{~m}^{2}$ \\
5. Balai Pertemuan Nelayan & \\
\hline Fasilitas Pendukung & $110.00 \mathrm{~m}^{2}$ \\
1. Mushollah + KM/WC Umum & \\
2. Failitas Pengolahan Bandeng & $432.00 \mathrm{~m}^{2}$ \\
\multicolumn{1}{|c|}{ Cabut Duri } & $500 \mathrm{~m}^{2}$ \\
\hline 3. Area Parkir & $\mathbf{2 . 8 8 1 \mathrm { m } ^ { 2 }}$ \\
\hline $\begin{array}{l}\text { Total Luas Bangunan } \\
\text { *luas bangunan sudah termasuk sirkulasi } \\
\text { 30\% }\end{array}$ & \\
\hline
\end{tabular}

Sumber: dokumentasi pribadi

\subsection{Analisis Tapak}

Analisis tapak yag dilakukan dan hasil analisis tapak adalah sebagai berikut 
a. Pada area site matahari cukup terik, sehingga antisipasi yang dilakukan untuk menanggulangi panas serta mengatur suhu agar tidak terlalu panas adalah dengan menambah vegetasi pada area-area yang membutuhkan peneduh serta adanya kolam yang bertujuan untuk mengurangi rasa panas.

b. Intensitas angin yang cukup tinggi dimanfaatkan sebagai penyejuk dengan memberi banyak bukaan pada bangunan, sehingga dapat mengurangi panas dan suhu lembab pada ruangan. Orientasi bangunan menghadap ke arah utara dan selatan untuk mengoptimalkan sirkulasi udara didalam ruangan.

c. Kebisingan tinggi berasal dari jalan raya yang merupakan arus transportasi kendaraan umum yang berada di area sebelah barat site. Agar tidak mengganggu kenyamanan maka area yang memiliki intensitas kebisingan tinggi akan dinetralisir dengan diberikannya beberapa sirkulasi ataupun vegetasi dan menjauhkan objek bangunan terhadap zonifikasi kebisingan pada area tersebut.

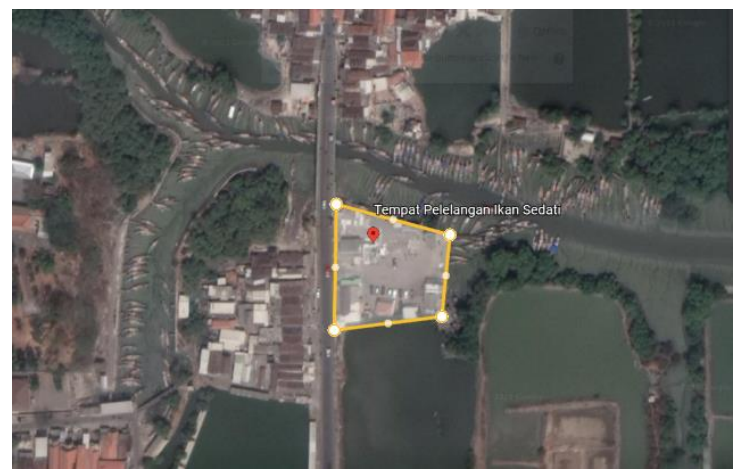

Gambar 7. Lokasi Site TPI Juanda di Tambak Cemandi, Sidoarjo

Sumber: google maps

\subsection{Program Rancangan}

Program rancangan menggunakan Teori dari Donna P. Duerk dalam Prameswari dan Ardianta (2016) yaitu dengan cara pengumpulan, pengorganisasian, analisis, penafsiran, dan menguraikan informasi yang relevan terkait proyek Tempat Pelelangan Ikan dan Wisata Kuliner di Tambak Cemandi, Sidoarjo ini. Pada program rancangan ini. Pada program rancangan ini juga melakukan pendekatan rancangan dari beberapa permasalahan yang ada untuk memperoleh tujuan yang diinginkan dengan menghasilkan suatu rancangan yang lebih terarah. (Ardianta, Prameswari, Bernadette dan Defry, 2016)

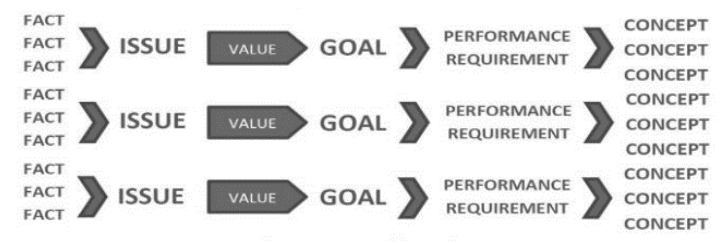

Gambar 8. Alur Program Rancangan

Sumber: Prameswari dan Ardianta (2016)

\subsection{Konsep Desain}

Perumusan konsep dapat dimulai dengan mengembangkan hasil partial ide yang berupa aspek kecil dari program rancangan dan kemudian membangun keseluruhan konsep dengan menggabungkan semua bagianbagian kecil tersebut. Bagian kecil tersebut dapat dijadikan acuan sebagai hasil mikro konsep dengan mengaitkannya dengan tema yang diambil sehingga dapat menemukan ide mikro konsep tatanan lahan, bentuk dan ruang. Konsep rancangan ini menjelaskan mulai dari penarikan makro konsep “arsitektur alami” dengan mikro konsep "atraktif” pada bentuk, "adaptif fungsional” pada mikro konsep ruangnya, dan "terarah" pada mikro konsep tatanan lahan. 


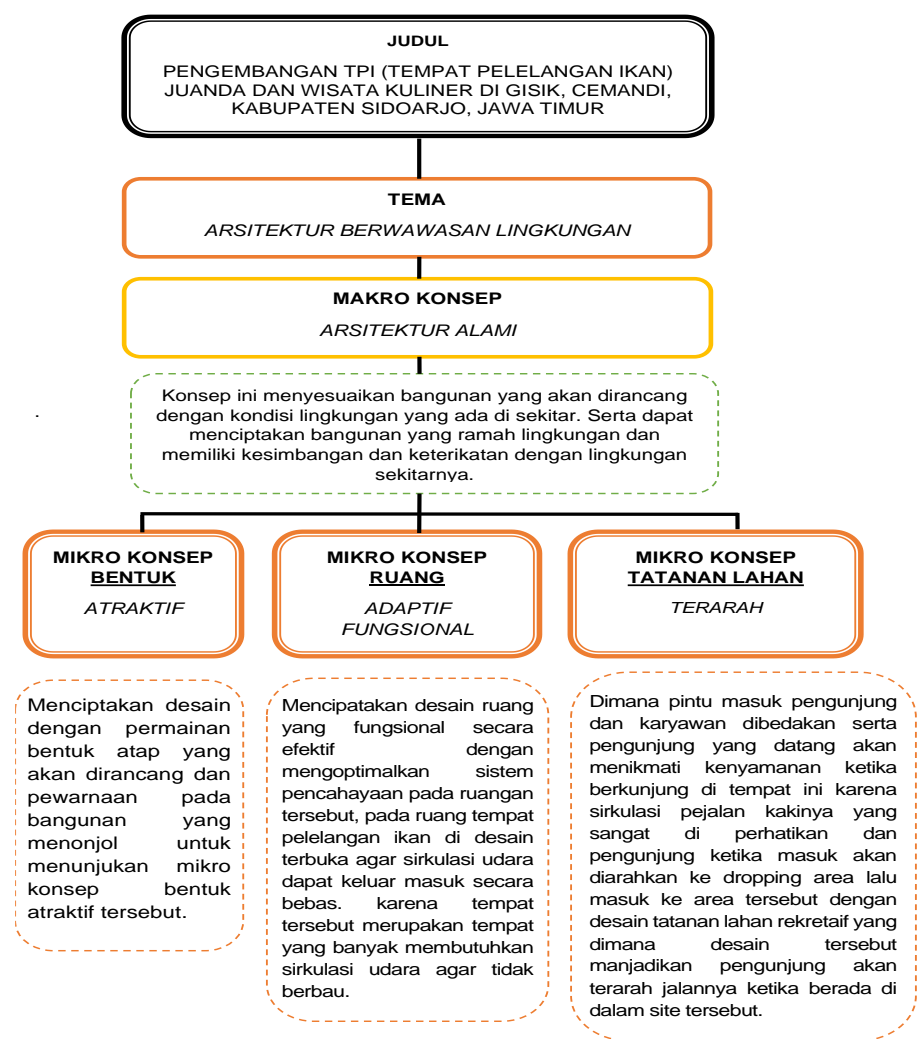

Gambar 9. Hirarki Konsep

Sumber: dokumen pribadi

\section{Kesimpulan}

Dari Tema Berwawasan Lingkungan Pada Konsep Desain Pengembangan Tempat Pelelangan Ikan dan Wisata Kuliner di Tambak Cemandi, Sidoarjo ini adalah tempat pelelangan ikan yang sangat potensial untuk dikembangkan sebagai destinasi wisata dan sangat menarik juga digunakan sebagai tempat wisata kuliner. Pemasaran Ikan pada TPI Tambak Cemandi ini juga merupakan sebuah fasilitas untuk pelelangan ikan yang dikelola secara langsung oleh orang TNI AL di Kabupaten Sidoarjo. Tempat pelelangan ikan ini berdiri diatas lahan 1.5 Ha. Pemasaran Ikan Juanda berada dipinggiran sungai besar yang mengarah ke laut.

Dikembangkannya TPI (Tempat Pelelangan Ikan) Tambak Cemandi dan wisata kuliner ini diharapkan agar pengunjung dan pegawai ketika berada disitu merasakan kenyamanan dengan bentukan desain bangunan yang atraktif, ramah lingkungan, dilengkapi fasilitas yang terpadu sehingga masyarakat tertarik untuk mengunjunginya. Serta mengolah lahan yang terbatas dengan se menarik dan se nyaman mungkin. Menyediakan sarana dan prasarana seperti keamanan, kemudahan, serta memberikan kenyamanan dalam melakukan proses di TPI Tambak Cemandi dan tempat wisata kuliner tersebut.

\section{Referensi}

Azizah, S. (2018). Pengembangan Pusat Kuliner Di Pusat Kota Ditinjau Dari Aspek Desain Bangunan. $\begin{array}{llllll}\text { Prosiding Semnas } & \text { PPM 2018, } 1483-1488 .\end{array}$ http://prosiding.lppm.unesa.ac.id/index.php/semnasppm2018/article/view/161

Echols, J. M., \& Shadily, H. (2014). Kamus Inggris-Indonesia. Gramedia Pustaka Utama.

Frick, Heinz; Suskiyanto, FX. Bambang (Penerjemah). 2007. Dasar-dasar Arsitektur Ekologis, Yogyakarta: Kanisius.

Lexy. J. Moleong. 2000. "Metodologi Penelitian Kualitatif." Bandung: PT Remaja Rosdakarya. hlm. 3 Prameswari, Bernadette H dan Ardianta, Defry A, 2016. "Arsitektur dan teori Multiple Intelligences Sebagai Pemicu Kreativitas.” Jurnal Sains dan Seni ITS, vol. 5, no 2, ITS, Surabaya.

Putri, I. . T. E., Sulistyawati, A. S., Suark, F. M., \& Ariani, N. M. (2013). Pengembangan Makanan Khas 
Bali Sebagai Wisata Kuliner di Desa Sebatu Kecamatan Tegalalang Gianyar. Jurnal Udayana Mengabdi.

Rahmi, N., Widjajanti, W. W., Poedjioetami, E., Arsitektur, J., Teknik, F., \& Itats, P. (2019). Teluk Harapan Pulau Maratua Kalimantan Timur Tema : Arsitektur Berwawasan Lingkungan. Teknologi Perencanaan, Perancangan, Lingkungan, Dan Infrastruktur, 2(1), 259-265.

Sharma, M. P., \& Dhanwantri, M. K. (2017). Application of Materials in Interior Design. International Education Applied Scientific Research Journal, 2(7). http://ieasrj.com/journal/index.php/ieasrj/article/view/52

Wibisono, W. (2005). Peran dan Strategi Koperasi Perikanan dalam Menghadapi Tantangan Pengembangan TPI dan PPI di Indonesia Terutama di Pulau Jawa. Semiloka Internasional Tentang Revitalisasi Dinamis Pelabuhan Perikanan Dan Perikanan Tangkap Di Pulau Jawa Dalam Pembangunan Perikanan Indonesia, Bogor. 